\title{
Helping People to Manage and Share Their Digital Information: A Role for Public Libraries
}

\author{
Andrea J. Copeland and Deborah Barreau
}

\begin{abstract}
As a cultural institution, the public library is charged with providing resources and services that fit the needs of a particular community and, if space and budgets allow, of serving as a resource and repository of the community's past. To fulfill its mission to the public, the library must attract that public by offering materials and providing opportunities for them to pursue their unique and varied interests and discover new things. By engaging individuals in the identification and preservation of their own personal, digital objects, it may be possible to increase awareness in, and commitment to, community repositories that reflect a community's diversity and that will serve all. A user education program that focuses on the importance of identifying and preserving the information and artifacts that are important, that addresses the technical aspects of preservation, and that creates awareness of the benefits and challenges associated with sharing personal information can result in a community repository that ultimately has more value for both the individual and the community.
\end{abstract}

"All lives need stories near at hand, and our experiences of narratives in contextually rich worlds are transformative."

—David Carr, The Promise of Cultural Institutions, p. 57

\section{INTRODUCTION}

The vision of libraries and archives as "the most purposeful and intentional of institutions ... holding the culture's memory and minding its continuing community" (Carr, 2003, p. 113) is an ideal we willingly em- 
brace. We can provide, at minimum, anecdotal evidence for how libraries and archives have preserved culture and transformed lives (American Libraries, 1993; Woman's Day, 2007). Yet some have suggested that rather than serving our diverse communities, reflecting local tastes and character, libraries serve mainstream interests, acquiring and preserving items that might be found in any collection (Danky, 1997). Whether one accepts the former, the latter, or some other view, the increasing predominance of digital over analog formats (Lyman \& Varian, 2003) offers an opportunity to reexamine our institutional role and perhaps reclaim it. Individual digital information management practice falls increasingly under the auspices of Google and Microsoft (Carr, 2008), but we suggest that libraries offer a more appealing opportunity to connect individuals through a multifaceted approach involving education, technology, and shared expertise that will result in "co-created community repositories."

Individuals are amassing large amounts of digital content because they have access to inexpensive and seemingly endless storage capability as well as to high-speed computing for facilitating the creation and acquisition of digital content (Beagrie, 2005). Evidence suggests that limited infrastructure, limited knowledge about digital preservation, and the everchanging personal computing environment increase the danger that individuals will lose valuable representations of personal memories (Jones, 2007; Kaye et al., 2006; Marshall, 2008).

Studies of personal information management (PIM) have found that although most people save and back up digital files, few create archives in the traditional sense. There may be benefits in making people aware of the importance of effective archival practice (Boardman \& Sasse, 2004), yet few have suggested how individuals will learn best practices for organizing and preserving their files. While there are sources willing to host personal, and even shared, document collections for free (Google Docs, for example), none has offered much guidance for organizing, evaluating, and preserving these items for long-term use or for examining the social and legal issues related to their use.

Public libraries and other memory organizations are potentially excellent sources for informing individuals about best PIM practices. Public libraries are either gaining or creating state-of-the-art knowledge as they develop and maintain their own digital collections and make those collections accessible to others (Bradley, 2007; Cole \& Shreeves, 2004; Mason, 2007). Public libraries are a vital part of communities (Agosto, 2007; Sullivan, 2003) and of the information economy, and they are in position to create connections between the two (Abend \& McClure, 1999; Urban Libraries Council, 2007). Public libraries already serve the role of educating users through information literacy skills programs (Eisenberg, Lowe, $\&$ Spitzer, 2008). Public libraries and other memory organizations are creating digital collections of local significance that could easily attract the 
involvement of community members (Dalbello, 2004). Finally, as cultural institutions whose greatest responsibility is to the communities they serve, libraries can benefit from increased engagement of the individuals who live there (Zweizig \& Dervin, 1977).

The story of a community is more than the official version recorded in newspapers and formal documents. Individuals often experience events differently or provide a point of view counter to the mainstream. Personal diaries, photographs, letters, etc., have often shared a different truth or have provided details otherwise unavailable. Stored in boxes, albums, and notebooks, these items, especially those of important people, have sometimes been donated to archives where they are available to scholars, but are relatively inaccessible to anyone else. Although digital media are in some ways more ephemeral than paper, the relatively small size of the files, flexibility of the format, and the large quantity of materials generated increase their potential for use.

People provide knowledge of local history, customs, and events; provide diverse points of view; and often have a personal interest in supporting community organizations. Anyone with a digital camera, a computer, or even a cell phone is generating content that may potentially add to our knowledge base or represent an otherwise undocumented point of view. Yet individuals struggle with what to keep, where to put it, how to organize it, and how to find it later (Barreau, 1995; Bernstein, Van Kleek, Karger, \& Schraefel, 2008; Jones, 2008; Marshall \& Jones, 2006). Library and information professionals working through their organizations have the technical expertise and the technical infrastructure to help individuals capture and preserve their digital records and to facilitate co-creation of a community repository (Japzon, 2008; Russo \& Watkins, 2007).

We propose a framework for exchanging knowledge that will address the social, legal, and technical aspects of managing personal, digital information over a lifetime, as well as the cultural, social, and historical benefits of sharing this information. The framework links the creation of artifacts by individuals, commentary on and use of the artifacts by others, and the skills of library and information science professionals who can facilitate participation through instruction. We will discuss the following areas for exploration: local cultural heritage, privacy, copyright, organization, classification, selection, appraisal, file format, and storage media.

\section{Co-Created Community Repository Framework}

The Co-Created Community Repository Framework ${ }^{1}$ supports three community components:

- Community residents who, throughout their lives, acquire or create artifacts, some of which are born digital and some that they may wish to digitize, including: 
a. things that are private, personal, or to be shared only with selected individuals, and

b. things that have broad appeal that may be shared with the public

- Information professionals who work in cultural institutions such as libraries, historical societies, and archives and who may possess the skills, tools, and the infrastructure to enable community residents to create and/or contribute digital records

- Community residents (current and future) who use the resources, generate different views to resources, offer commentary, and perhaps contribute their own resources in return.

Examples of such community projects include the Eckhart Public Library in Auburn, Indiana (Indiana University, 2010), and, on a broader scale, the New Jersey Digital Highway (n.d.).

\section{Documenting Local Cultural Heritage}

The importance of cultural heritage and digital collections has been discussed with respect to subject content (Dalbello, 2004); political implications (Cloonan, 2007; Lloyd, 2007); partnering with other memory organizations to harness the collective cultural resources within a community (Bauer \& Carlin, 2003); organization of materials (Wendler, 2004); digitization of materials (Perry, 2005); promotion and access (Bishop, Van House, \& Buttenfield, 2003); and cultural learning opportunities for students (Powell, 2005; Taylor, 2003). While much less has been written on the inclusion of community members in the creation of collections that document local, cultural heritage (Horton, 2001; Kaplan, 2000), we intend to illustrate ways in which public libraries can document and preserve the cultural heritage of their specific communities through the social and technical infrastructure of digital libraries.

Archives have traditionally dealt with issues related to documentation and preservation, and libraries with issues related to collection and access. The creation of digital collections in libraries and archives has helped these two professional approaches consider the importance of each within its own context (Chowdhury, 2010; Moghaddam, 2010); archives are becoming more concerned about access and libraries are becoming more concerned about preservation. The co-created community repository framework places equal importance on access and preservation and makes community members themselves, rather than specific events or places, the subject of these co-created collections. This approach will be more inclusive of community members as it focuses on the experiences of those members rather than on some event or place that may have meaning for some, but not for all. Further, by focusing on the living, co-created community repositories can begin to address the challenge of collecting tomorrow's digital history today. 
Traditionally, archivists have focused their acquisition efforts on historical rather than current materials (Rosenzweig, 2003) and on print or physical materials rather than on digital resources (Burton, 2002, 2005). The potential for archives to continue to fulfill their role as preservers of our collective cultural heritage in the digital era is threatened when one considers the intrinsic quality of digital materials. Among these intrinsic qualities is the difficulty in distinguishing the type, source, provenance, and value of data stored on the same digital medium.

\section{Privacy and Copyright}

Issues related to privacy and copyright are inherent to all personal information residing in archives, repositories, and in personal collections on the Web (Besek, 2003). Through the knowledge exchange process of the cocreated community repository, LIS professionals can share their expertise related to these issues (Besek, 2003; Schwarz, 1992). Community members will have to decide which of their personal documents have public value and which are best kept private. Through the help of LIS professionals, public library users can begin to understand the scope of the unique collections contained within the collective (Gaudette, 2003/2004).

With regard to copyright and digital information generally, there are issues yet to be resolved in the courts (Electronic Frontier Foundation, 2008). These issues, as they are resolved, will affect an individual's rights and responsibilities regarding the use, storage, and creation of digital information. The co-created community repository framework provides a platform from which public library users can begin to understand their roles as individuals in practicing information behaviors that are respectful of their personal rights as well as the rights of others.

\section{Organization and Classification}

Several research studies have found that individuals distribute their digital information across many devices and Web locations with no technical means of unifying access or comprehensively searching all their personal digital information (Bergman, Beyth-Marom, \& Nachmias, 2006; Japzon 2009; Jones, 2004). Over time, this disorganization will inhibit access as cognitive association with the location of personal information will fade (Bartlett, 1932, 1958), especially given the importance of using current context to classify and organize personal information (Barreau, 1995; Barreau \& Nardi, 1995; Japzon, 2009; Kwasnik, 1989).

Research also indicates that behaviors that contribute to the organization of personal information have limitations of scale (Barreau, 1995; Elsweiler, Baillie, \& Ruthven, 2008; Japzon, 2009). ${ }^{2}$ These behaviors are likely to inhibit access to personal information over time given the paucity of metadata created for refinding personal content and the technical barriers to integrating browsing and/or searching of all personal information. Ultimately, system design and individual practices will need to be altered 
as reliance on digital information is likely to increase. We suggest that through co-created repositories, public library users can begin to understand the implications of their actions and of the systems they are using. With this understanding, they can effectively provide for long-term access to their digital information.

\section{Selection and Appraisal}

When individuals decide to select or keep digital information, the amount of organizational effort expended during selection may affect the amount of time they spend later when they attempt to refind/retrieve information from their personal information store. When individuals remember the location of a specific information item in their collections, it is likely due to some explicit act of keeping (Jones, 2004). As Lansdale (1988, p. 468) noted, "The two steps of information recall and recognition can be viewed as a dialogue between people and their information environments." The success of finding/retrieving information depends on individuals remembering what to look for and where to look for it. Remembering that an information item is stored within a personal collection must precede recall.

To study the relationship between selecting and retrieving personal digital information, Barreau (1995) framed her research in terms of four overarching behavioral areas: acquisition or selection, organization, refinding and/or retrieval, and maintenance. The acquisition of an item can be deliberate or unsolicited. Selections that are deliberate reflect a personal anticipated information need (Bruce, 2005). Individuals select and store information with the intent to use the item in the future. Presumably, there is an appraised value associated with information selected and stored for future use.

In addition to the cognitive associations built around selecting and storing personal information, memory is aided by keeping selected items in view. Barreau and Nardi (1995) found that users of personal computers purposely locate items to facilitate remembering, for example, using icons on desktops and sending e-mail notes to oneself.

As the volume of personal digital information stored by individuals increases and the types of storage devices and locations become more numerous, it will be increasingly difficult for individuals to manage or see all of their information items at once. Some researchers advocate that individuals keep everything and discontinue expending effort to make selections and create organizational/classification schemes for their personal information (Cutrell, Dumais, Teevan, 2006; Gemmell, Bell, \& Lueder, 2006). However, reliance on search may not be helpful for refinding information over long periods of time, especially given what is known about the importance of cognitive associations and the functioning of memory (Davies \& Thomson, 1988; Kelly \& Chen, 2008; Sellen et al., 2007). 
Jones (2004) recommends creating a personal unifying taxonomy to integrate information organization across devices. Marshall (2008) recommends using a federated search mechanism to unify access to metadata applied to personal digital information. Anderson, Hodge, and Japzon (2007) provide a framework for a metadata repository that combines the application of a unifying taxonomy and a federated search for the retrieval of digital content distributed in various networked locations. Each of these possibilities has its limitations. Through the knowledge exchange that takes place during the development of a co-created community repository, we assert that there is a role for LIS professionals to share with public library users their knowledge of the limitations inherent in each of these approaches. If individuals are encouraged to identify digital information of value to them, LIS professionals could then begin to teach public library users how to identify and preserve digital information of value to them through established curatorial practices.

The curatorial process would encourage individuals to appraise the information contained in their personal stores and then make decisions on how best to take care of selected information over the long term (see, e.g., Petrelli, van den Hoven, \& Whittaker, 2009). We assert that shared information is valued information, and this idea can be realized in the co-creation of community repositories. As people see what others have chosen to share, they may be motivated to share similar types of things as well as to comment on things that are shared by others.

\section{File Formats and Storage Media}

In her study of public library users $(N=26)$ and their digital preservation behaviors, Japzon (2009) found that most of the study participants lacked specific knowledge about which storage devices, locations, or file formats were considered best for providing long-term access to their digital content. She found that most of the participants made decisions related to file formats and storage based on ease of use and the constraints of the devices and software programs they were using. These results demonstrate that there are potential benefits in educating the public about digital preservation, and these educational programs may best be offered through public libraries.

In Best Practice Guidelines for Digital Collections, the University of Maryland Libraries differentiates between archival formats, which are intended to support long-term use and access, and Web deliverable formats, which are intended to support current and dynamic use and access. The guide states the following general requirement for archival file formats: "a format that is open (non-proprietary) and well-documented, widely supported, and cross-platform compatible" (Office of Digital Collections and Research, 2007). The Electronic Literature Organization provides a pamphlet both online and in print that encourages authors to publish and work in AcidFree Bits (Montfort \& Wardrip-Fruin, 2004). 
The use of open systems and formats will allow for the creation of standards. Such standards promote interoperability among systems and this interoperability will increase possibilities for resource discovery and preservation. Recommendations on the file formats that are best for longterm access have been made by such agencies as the Digital Preservation Coalition in the United Kingdom (http://www.dpconline.org/) and the Florida Center for Library Automation Digital Archive in the United States (2010). Through the creation of co-created community repositories, public library users will have access to resources on file formats and standards that they may apply to their own personal information collections.

Ideally, public library users and other consumers will have accessible and understandable information on the most reliable and most appropriate storage devices and locations. A storage selection guide is part of a digital preservation workbook created for professional archivists by the United Kingdom Research project, PARADIGM (2008). Agencies such as the National Institute of Standards and Technology, the Image Permanence Institute, and InterPARES have produced guides on the care and handling of digital storage media for professional audiences. While a variety of research has been conducted on the longevity of storage media (Porck \& Teygeler, 2000) and varied resources have been produced, a consumer-level resource intended for public library users has yet to be created.

As with file formats, we assert that through the creation of co-created community repositories, resources on storage media preferred for longterm access can be made understandable to public library users and the knowledge gained can be applied to their own personal information collections.

\section{Discussion And Concludsion}

The growing dependency on, and preference for, digital formats have implications for the production, access, and storage of information sources. How much longer will publishers have the economic means to produce and provide the same content in multiple formats? Likewise, will libraries be able to justify the purchase and storage of multiple formats containing the same content? Better technologies will likely win out.

As the use of digital information for communication and documentation becomes the norm rather than an option, then reliable, affordable, and trusted stores of digital information will be needed to record personal and social histories. The cost of digital information production and access will continue to decrease such that the major associated costs will be related to preservation. This is where the role of public libraries may incorporate preservation for the public good in addition to their established roles of promoting information access and lifelong learning. 
Libraries have kept pace with technological change in order to meet the expectations of their constituents. Most libraries provide access to digital information in a variety of formats and delivery options. But at some point in the future, providing access to digital information may no longer be primarily the role of libraries, especially if Google Scholar and Books are harbingers of the types of information sources to come. Also, as production and publication functions increasingly merge, the need for information intermediaries to select, acquire, and provide access to information may be decreasing (Janes, 2003).

The library's primary role of collecting information has evolved to focus on providing access, but public libraries may focus once again on collecting if the need to preserve digital information is perceived as a public good. Long-term access to our collective cultural heritage is not a commodity for sale and therefore may be of little interest to publishers. The responsibility and cost for digital preservation is too great for any one person, institution, or marketplace to bear. As libraries have traditionally made materials available to those who can least afford them, they may also help individuals appreciate the value of personal artifacts and help them to preserve and share those treasures.

To create a sustainable infrastructure for digital preservation, libraries and other memory institutions must create interoperable systems and develop standards for creation and storage (Bradley, 2007; Mason, 2007). Otherwise, how will individuals know what practices are best for storage and file formats and where their valued personal digital information should reside?

Public libraries can work with their constituents to support the preservation of personal information and the selection of items that may contribute to social and cultural histories. Collection creation, maintenance, and preservation (physical or digital) are knowledge intensive processes, and public libraries are trusted and experienced sources for these functions. As such, they are logical candidates to facilitate community repository development.

Generally, public libraries have connected with users by providing access to materials, to computers, and to networked proprietary resources for personal use, but have not succeeded as well at connecting with individuals in their personal computing spaces. Further research is needed to understand how libraries can forge connections between people and their valued digital information. By helping individuals identify digital objects that are important to them and by increasing awareness of the technological challenges associated with digital object management, librarians and LIS researchers can become a driving force behind helping the public to preserve and organize their personal information collections. 


\section{Notes}

1. Russo and Watkins (2007) described "community co-creation" as cultural institutions and communities working together to create digital content, each benefiting and learning from the other's expertise and experience.

2. Personal information behaviors are characterized by: file and folder classification that is inspired by the current context of the information use; folder organizational strategies that are informal and idiosyncratic; organization that relies on broadly classified folders to order and define content topicality; limited use of metadata based primarily on current context; and photographs that are identified at the folder level without item level description.

\section{REFERENCES}

Abend, J., \& McClure, C. (1999). Recent views on identifying impacts from public libraries. Public Library Quarterly, 17(3), 3-29.

Agosto, D. E. (2007). Why do teens use libraries? Results of a public library use survey. Public Libraries, 46(3), 55-62.

American Libraries. (1993). Actors, writers, sports stars agree: Libraries do change lives. American Libraries, 24(4), 304.

Anderson, N., Hodge, G., \& Japzon, A. (2007). Harnessing NASA Goddard's grey literature: The power of a repository framework. The Grey Journal, 3(3), 154-158.

Barreau, D. (1995). Context as factor in personal information management systems. Journal of the American Society for Information Science, 46(5), 327-339.

Barreau, D., \& Nardi, B. (1995). Finding and reminding: File organization from the desktop. ACM SIGCHI Bulletin, 27(3), 39-43.

Bartlett, F. (1932). Remembering: An experimental and social study. Cambridge: Cambridge University Press.

Bartlett, F. (1958). Thinking. New York: Basic Books.

Bauer, C. \& Carlin, J. (2003). The case for collaboration: The OhioLINK Digital Media Center. Journal of Library Administration, 39(2), 69-86.

Beagrie, N. (2005, June). Plenty of room at the bottom? Personal digital libraries and collections. D-Lib Magazine, 11(6). Retrieved December 1, 2010, from http://www.dlib.org/ $\mathrm{dlib} /$ june05/beagrie/06beagrie.html

Bergman, O., Beyth-Marom, R., \& Nachmias, R. (2006). The project fragmentation problem in personal information management. In R. Grinter, T. Rodden, P. Aoki, E. Cutrell, R. Jeffries, \& G. Olson (Eds.), Proceedings of the SIGCHI Conference on Human Factors in Computing Systems (pp. 271-274). New York: ACM.

Bernstein, M., Van Kleek, M., Karger, D., \& Schraefel, M. C. (2008). Information scraps: How and why information eludes our personal information management tools. ACM Transactions on Information Systems, 26(4), article 24.

Besek, J. (2003). Copyright issues relevant to the creation of a digital archive. Mircoform $\mathcal{E}$ Image Review, 32(3), 86-96.

Besek, J. (2005). Copyright issues relevant to digital preservation and dissemination of pre-1972 commercial sound recordings by libraries and archives. CLIR Publication 135. Washington DC: CLIR.

Bishop, A., Van House, N., \& Buttenfield, B. (2003). Digital library use: social practice in design and evaluation. Cambridge, MA: MIT Press.

Boardman, R., \& Sasse, M. A. (2004). "Stuff goes into the computer and doesn't come out": A cross-tool study of personal information management. In E. Dykstra-Erickson \& M. Tscheligi (Eds.), Proceedings of ACM CHI 2004 Conference on Human Factors in Computing Systems (pp. 583-590). New York: ACM.

Bradley, K. (2007). Defining digital sustainability. Library Trends, 56(1), 148-163.

Bruce, H. (2005, April). Personal, anticipated information need. Information Research, 10(3). Retrieved December 12, 2010, from http://informationr.net/ir/10-3/paper232.html on February 10, 2007.

Burton, O. (Ed.). (2002). Computing in the social sciences and humanities. Chicago: University of Illinois Press.

Burton, O. (2005). American digital history. Social Science Computer Review, 23(2), 206-220. 
Carr, D. (2003). The promise of cultural institutions. Walnut Creek, CA: AltaMira Press.

Carr, N. (2008). The big switch: Rewiring the world from Edison to Google. New York: W. W. Norton.

Chowdhury, G. (2010). From digital libraries to digital preservation research: The importance of users and context. Journal of Documentation, 66(2), 207-223.

Cloonan, M. (2007). The paradox of preservation. Library Trends, 56(1), 746-755.

Cole, T., \& Shreeves, S. (2004). Search and discovery across collections: The IMLS digital collections and content project. Library Hi Tech, 22(3), 307-322.

Cutrell, E., Dumais, S.T., \& Teevan, J. (2006). Searching to eliminate personal information management. Communications of the ACM, 49(1), 58-64.

Dalbello, M. (2004). Institutional shaping of cultural memory: Digital library as environment for textual transmission. Library Quarterly, 74(3), 265-298.

Danky, J. P. (1997). Libraries: They would have been a good idea. Alternative Library Literature 1996/1997, 3-6.

Davies, G., \& Thomson, D. (Eds.). (1988). Memory in context: Context in memory. Chichester, UK: John Wiley \& Sons.

Eisenberg, M., Lowe, C., \& Spitzer. K. (2008). Information literacy: Essential skills for the information age. Santa Barbara, CA: Libraries Unlimited.

Electronic Freedom Foundation. (2008). Unintended consequences: Ten years under the DMCA. Retrieved December 12, 2010, from http://www.eff.org/files/DMCAUnintended10.pdf

Elsweiler, D., Baillie, M., \& Ruthven, I. (2008). Exploring memory in email re-finding. ACM Transactions on Information Systems, 26(4), article 21.

Florida Center for Library Automation. (2010, September 13). The Florida Digital Archive. Retrieved December 1, 2010, from http:/ / fclaweb.fcla.edu/FDA_landing_page

Gaudette, M. (2003/2004). Playing fair with the right to privacy. Archival Issues, 28(1), 2134.

Gemmell, J., Bell, G., \& Lueder, R. (2006). MyLifeBits: a personal database for everything. Communications of the ACM, 49(1), 89-95.

Horton, R. (2001). Cultivating our garden: Archives, community, and documentation. Archival Issues, 26(1), 27-38.

Indiana University, School of Library and Information Science. (2010, March 8). Digital community repository. Retrieved December 1, 2010, from http://slis.iu.edu/news/story .php?story_id=2117

Janes, J. (2003). What is reference for? Reference Services Review, 31(3), 22-25.

Japzon, A. (2008, August). A model of and support for a digital preservation infrastructure that connects individuals to libraries. In Proceedings of the World Library and Information Congress: 74th IFLA General Conference and Council. Retrieved December 1, 2010, from http:/ /www.ifla.org/IV/ifla74/papers/084-Japzon-en.pdf

Japzon, A. (2009). Exploration of the knowledge of and motivation for learning preservation practices for personal digital information. Unpublished doctoral dissertation. Drexel University, Philadelphia, PA. Retrieved December 1, 2010, from http://idea.library.drexel.edu/ bitstream/1860/3116/1/Japzon_Andrea.pdf

Jones, W. (2004). Finders, keepers? The present and future perfect in support of personal information management. First Monday, 9(3). Retrieved December 1, 2010, from http:// www.firstmonday.org/issues/issue9_3/jones/index.html

Jones, W. (2008). Keeping found things found: The study and practice of personal information management. Burlington, MA: Morgan Kaufmann.

Jones, W. (2007). Personal information management. In B. Cronin (Ed.), Annual Review of Information Science and Technology, Vol. 41. Medford, NJ: Information Today.

Kaplan, E. (2000). We are what we collect, we collect what we are: Archives and the construction of identity. American Archivist, 63(1), 126-151.

Kaye, J., Vertisi, J., Avery, S., Dafoe, A., Shay, D., Onaga, L., et al. (2006). To have and to hold: Exploring the personal archive. In R. Grinter, T. Rodden, P. Aoki, E. Cutrell, R. Jeffries, \& G. Olson (Eds.), Proceedings of ACM CHI 2006 Conference on Human Factors in Computing Systems (pp. 275-284). New York: ACM

Kelly, L., \& Chen, Y. (2008). A study of remembered context for information access from personal digital archives. In P. Borlund, J. Schneider, M. Lalmas, A. Tombros, J. Feather, D. Kelly, \& A. de Vries (Eds.), Proceedings of the second international symposium on Information interaction in context (pp. 44-50). New York: ACM. 
Kwasnik, B. (1989). The influence of context on classificatory behavior. Unpublished doctoral dissertation, Rutgers University, New Brunswick, NJ.

Lansdale, M. (1988). The psychology of personal information management. Applied Ergonomics, 19(1), 55-66.

Lloyd, A. (2007). Guarding against collective Amnesia? Making significance problematic: An exploration of issues, Library Trends, 56(1), 53-65.

Lyman, P., \& Varian, H. (2003). How much information 2003? Retrieved December 1, 2010, from http:/ /www2.sims.berkeley.edu/research/projects/how-much-info-2003/

Marshall, C. C. (2008). Rethinking personal digital archiving, Part 1: Four challenges from the field. D-Lib Magazine, 14(3/4). Retrieved December 1, 2010, from http://www.dlib .org/dlib/march08/marshall/03marshall-pt1.html

Marshall, C.C., \& Jones, W. (2006). Keeping encountered information. Communications of the $A C M, 49(1), 66-67$.

Mason, I. (2007). Cultural information standards: Political territory and rich rewards. In F. Cameron \& S. Kenderdine (Eds.), Theorizing Digital Cultural Heritage (pp. 223-244). Cambridge, MA: MIT Press.

Moghaddam, G. G. (2010). Preserving digital resources: Issues and concerns from a view of librarians. Collection Building, 29(2), 65-69.

Monfort, N., \& Wardrip-Fruin. (2004, June 14). Acid-free bits: Recommendations for long-lasting electronic literature. Version 1.0. Electronic Literature Organization. Retrieved December 1, 2010, from http://eliterature.org/pad/afb.html

New Jersey Digital Highway. (n.d.). Your personal story: Document and preserve your family history. Retrieved December 1, 2010, from http://www.njdigitalhighway.org/ personal_story_ever.php

Office of Digital Collections and Research, University of Maryland, College Park. (2007). Best practice guidelines for digital collections. Retrieved December 1, 2010, from http://www.lib .umd.edu/dcr/publications/best_practice.pdf

PARADIGM. (2008).Workbook on digital private papers. Retrieved December 1, 2010, from http:// www.paradigm.ac.uk/workbook/index.html

Perry, C. (2005, November). Education for digitization: How do we prepare? The Journal of Academic Librarianship, 31(6), 523-532

Petrelli, D., Van den Hoven, E., \& Whittaker, S. (2009). Making history: Intentional capture of future memories. In D. R. Olsen Jr., R. Arthur, K. Hinckley, M. Morris, S. Hudson, \& S. Greenberg (Eds.), Proceedings of the 27th International Conference on Human Factors in Computing Systems (pp. 1723-1732). New York: ACM.

Porck, H., \& Teygeler, R. (2000, December). Preservation Science Survey. Retrieved December 1, 2010, from http://www.clir.org/pubs/reports/pub95/contents.html

Powell, T. (2005, Summer). Digitizing Cherokee culture: Libraries, students, and the reservation. MELUS, 30(2) 79-100.

Rosenzweig, R. (2003). Scarcity or abundance? Preserving the past in a digital era. The American Historical Review, 108(3). Retrieved December 12, 2010, from http:/ /www.historycooperative .org/journals/ahr/108.3/rosenzweig.html

Russo, A., \& Watkins, J. (2007). Digital cultural communication: Audience and remediation. In F. Cameron \& S. Kenderdine (Eds.), Theorizing Digital Cultural Heritage (pp. 149-164). Cambridge, MA: MIT Press.

Schwarz, J. (1992). The archivist's balancing act: Helping researchers while protecting individual privacy. Journal of American History, 79 (1), 179-189.

Sellen, A., Fogg, A., Aiken, M., Hodges, S., Rother, C., \& Wood, K. (2007). Do life logging technologies support memory for the past? An experimental study using SenseCam. In M. Rosson \& D. Gilmore (Eds.), Proceedings of the 2007 Conference on Human Factors in Computing Systems (pp. 81-90). New York: ACM.

Sullivan, M. (2003). The fragile future of public libraries. Public Libraries 42(5), 303-308.

Taylor, B. (2003, January). Enhancing the value of museum web Sites: Lessons from the practical engagement front. Journal of Library Administration, 39(2\&3), 107-122.

Urban Libraries Council. (2007). Making cities stronger: Public library contributions to local economic development. Evanston, IL: Urban Libraries Council. Retrieved December 1, 2010, from http://www.urbanlibraries.org/files/making\%5Fcities\%5Fstronger.pdf 
Wendler, R. (2004). The eye of the beholder: Challenges of image access and description at Harvard. In D. Hilmann \& E. Westbrooks (Eds.), Metadata in Practice (pp. 51-60). Chicago: ALA.

Woman's Day (2007). "The library changed my life." Woman's Day, 70(6), 136-141.

Zweizig, D., \& Dervin, B. (1977). Public library use, users, uses: Advances in knowledge of the characteristics and needs of the adult clientele of American public libraries. Advances in Librarianship, 7, 231-255.

Andrea J. Copeland is an assistant professor in the School of Library and Information Science at Indiana University at Indianapolis. She received a PhD from Drexel University in information studies in September 2009. The digital preservation practice of public library users is the subject of her dissertation. Her studies at Drexel were supported by the Laura Bush 21st Century Librarian Fellowship from the Institute of Museum and Library Services. She was also the recipient of the Society of Woman Geographers Fellowship in 2002 for her research on the variation of public library use in New York City neighborhoods.

Deborah Barreau is an associate professor in the School of Information and Library Science at the University of North Carolina at Chapel Hill. Her research interests include organizational communication and personal information management. 